\title{
Awareness of food allergies: a survey of pediatricians in Kuwait
}

\author{
Waleed Al-Herz ${ }^{1,2^{*}}$, Khalid Husain ${ }^{3}$, Ahmed Al-Khabaz ${ }^{4}$, Mohamed A. A. Moussa ${ }^{5}$ and Fawaz Al-Refaee ${ }^{6}$
}

\begin{abstract}
Background: Early diagnosis of food allergies (FA) is important for a favorable prognosis. This study aimed to determine the level of awareness of FA among pediatricians in Kuwait.

Method: A 43-item self-administered questionnaire was designed and distributed to pediatricians working at 4 government hospitals in Kuwait.

Results: A total of 140 pediatricians completed the questionnaire, with a participation rate of $51.1 \%$ (81 males and 59 females). The mean age of participants was 40.81 years, and the mean number of years working in pediatrics was 13.94 years. The mean overall knowledge score was 22.2. The pediatricians' overall knowledge scores were found to be significantly associated with their age (older pediatricians had higher overall scores) and years of experience as a pediatrician but were independent from hospital site, gender, or rank. A multiple linear regression revealed pediatrician age and gender were the only variables that were significantly associated with the overall knowledge score. Only $16.4 \%$ of the participants answered at least $2 / 3$ of the survey questions correctly. The questions that were correctly answered by $\leq 2 / 3$ of the participants constituted $80 \%$ of clinical presentation questions, $66.6 \%$ of diagnostics questions, $77.7 \%$ of treatment questions, and $42.8 \%$ of prevention questions. Interestingly, among 68 pediatricians (48.5\%) who determined that they felt comfortable evaluating and treating patients with FA, only 12 (17.6\%) passed the questionnaire.
\end{abstract}

Conclusions: This survey demonstrates that there is a noteworthy deficiency of pediatricians' awareness about FA. The implementation of strategies to improve pediatricians' awareness is critical to diagnose food allergy patients early and improve their health and outcomes.

Keywords: Diagnosis, Epidemiology, Food allergy, Knowledge, Survey

\section{Background}

Food allergies (FA) are defined as an adverse reaction to food mediated by an immunologic mechanism involving specific IgE mechanisms (IgE-mediated), cell-mediated mechanisms (non-IgE-mediated), or both IgE- and cellmediated mechanisms (mixed IgE- and non-IgEmediated) [1]. FA most often begins in the first 2 years of life and can cause serious or even fatal reactions. In recent years, the prevalence of FA and its severity and complexity are increasing worldwide [2-4]. FA may affect approximately $8 \%$ of children younger than 3 years

\footnotetext{
*Correspondence: wemh@hotmail.com

'Department of Pediatrics, Faculty of Medicine, Kuwait University, P.O. Box: 24923, Safat, 13110 Kuwait city, Kuwait

${ }^{2}$ Allergy and Clinical Immunology Unit, Department of Pediatrics, Al-Sabah Hospital, Kuwait City, Kuwait

Full list of author information is available at the end of the article
}

of age, while the prevalence in children with FA associated with eczema is estimated to be as high as 30\% [5]. Early diagnosis of FA is crucial for a good prognosis and should lead to proper nutritional management. Parentperceived FA are common in early childhood, with up to one-third of parents reporting one or more adverse food reactions $[6,7]$. Families usually rely on pediatricians for early recognition of clinical manifestations of FA, and work-up of these patients often starts before referring the patients to specialists. A recent study showed that the mean time from the first physician visit to the diagnosis of cow milk allergy was almost 4 months [8]. Recent guidelines have been published by the European Academy of Allergy and Clinical Immunology to provide evidence-based recommendations for the diagnosis and management of FA for healthcare professionals [1]. 
Several surveys about pediatricians' and medical professionals' knowledge and practice about FA have been conducted [9-14]. Collectively, they showed deficiencies in knowledge of clinical presentations, appropriate use of diagnostic tests, and prescriptions for needed treatments. However, there is a lack of data about FA in the Middle East.

The primary aim of this study was to determine the level of food allergy knowledge and experience of pediatricians in Kuwait. We also aimed to identify the knowledge deficiency areas that need to be emphasized in order to facilitate the early and proper diagnosis of children with FA.

\section{Methods}

There are 6 government hospitals in Kuwait providing secondary and tertiary care to pediatric patients. A selfadministered questionnaire about FA was designed and distributed to pediatricians working at 4 government hospitals during December 2015. Five clinical immunologists and 10 gastroenterologists were excluded due to their expertise in FA. The questionnaire was divided into 5 sections:

- Demographic characteristics [age, gender, work-related variables (rank, years of experience as a pediatrician)]: 4 questions

- Clinical presentation: 10 questions

- Diagnostics: 12 questions

- Treatment: 9 questions

- Prevention: 7 questions

The questions in the clinical presentation, diagnostics, and treatment sections were based on the standards of care and the current practices of both allergists and gastroenterologists. The questions in the prevention section were based on the reports of the Adverse Reactions to Foods Committee of the American Academy of Allergy, Asthma, and Immunology and the National Institute of Allergy and Infectious Diseases-Sponsored Expert Panel $[15,16]$.

Finally, participants were asked whether or not they felt comfortable evaluating and treating patients with FA.

A correct answer was assigned one point, whereas a wrong or missing answer was given zero points. The overall knowledge score of each pediatrician regarding FA was computed by totaling the correct answers to the questions included in the clinical presentation, diagnostics, treatment, and prevention sections (38 questions in total). Participants were considered "passing" if their score was at least $67 \%$ (i.e., they answered at least $2 / 3$ of the questions correctly).

The Statistical Package for Social Sciences (IBM SPSS Statistics 23, IBM Corporation, Armonk, NY, USA, 2015) was used for data entry and analysis. The cut-off level for statistical significance was $p \leq 0.05$. The frequency distribution of the overall knowledge score of pediatricians regarding FA was tested for normality. The $t$-test was used to compare the mean overall knowledge score in binary socio-demographic characteristics (such as gender), while the one-way analysis of variance was used to compare the mean overall knowledge score in polychotomous variables such as rank and the different hospital sites. Pearson's correlation coefficient was used to assess the strength of association between the overall knowledge score and the two quantitative variables, age and duration of experience as a pediatrician. To eliminate confounding effects, the multiple linear regression method was used to identify the significant determinants of the overall knowledge score. The included variables were pediatrician age, gender, rank, hospital site, and years of experience as a pediatrician.

The study was approved by the Research and Ethics Committees of both the Health Sciences Center of Kuwait University and the Ministry of Health in Kuwait. Written informed consent was obtained from the pediatricians for inclusion in the study.

\section{Results}

A total of 274 pediatricians were invited to participate in the study, and $140(51.1 \%)$ responded to the questionnaire (81 males and 59 females) (Table 1). Their age (mean $\pm \mathrm{SD}$ ) was 40.81 years \pm 8.88 (range 26-67 years), and the mean number of years working as pediatricians was 13.94 years \pm 7.96 (range $1-42$ years). The distribution of the participants according to their rank was as follows: registrar: $53.6 \%$, senior registrar: $20.7 \%$, specialist: $5 \%$, senior specialist: $7.9 \%$, and consultant: $12.8 \%$.

The overall knowledge score was found to be normally distributed, with a mean of $22.2(\mathrm{SD}=3.4)$ and a $95 \%$ confidence interval of $21.7-22.8$ (Fig. 1 and Table 1). There was no significant difference between the mean overall knowledge score and the 4 hospital sites (Fig. 2, $p=0.347$ ). The pediatricians' overall scores were found to be significantly associated with their age (older pediatricians had higher overall scores) $(p=0.031)$ and the number of years of experience as a pediatrician $(p=0.003)$ but were independent from working at any of the hospitals, gender, or rank ( $p=0.347,0.106$, and 0.38 , respectively). Pediatrician age and gender were the only variables that were significantly associated with the overall knowledge score using multiple linear regression analysis $(p=0.018$ and 0.039 , respectively) (Table 2). For every 1 year increase in age, the overall knowledge score would increase by 0.147 . Females had a lower knowledge score by -1.373 compared to males.

Tables 3, 4, 5 and 6 show the questions included in different sections of the questionnaire with the percentages of participants who correctly answered them. A 
Table 1 Participation rate, pass rate, and knowledge score of pediatricians according to hospitals

\begin{tabular}{|c|c|c|c|c|c|}
\hline & All hospitals & Hospital 1 & Hospital 2 & Hospital 3 & Hospital 4 \\
\hline Participation rate \% & 51.1 & 83.7 & 56.7 & 21.8 & 45.6 \\
\hline Pass rate $\%$ & 16.4 & 16.1 & 21.1 & 15.8 & 9.5 \\
\hline \multicolumn{6}{|l|}{ Knowledge Score (Mean) } \\
\hline All sections (38questions) & 22.2 & 22.1 & 22.8 & 22.5 & 21.2 \\
\hline Clinical presentation (10 questions) & 6.1 & 6.2 & 6.1 & 5.9 & 6.1 \\
\hline Diagnostics (12 questions) & 5.3 & 5.3 & 5.0 & 5.5 & 5.5 \\
\hline Treatment (9 questions) & 6.2 & 6.2 & 6.5 & 6.4 & 5.5 \\
\hline Prevention (7 questions) & 4.7 & 4.5 & 5.2 & 4.7 & 4.1 \\
\hline
\end{tabular}

significant number of questions were correctly answered by $\leq 2 / 3$ of the participants. These responses constituted $80 \%$ of clinical presentation questions, $66.6 \%$ of diagnostics questions, $77.7 \%$ of treatment questions, and $42.8 \%$ of prevention questions.

Only $16.4 \%$ of the participating pediatricians passed the questionnaire (i.e., correctly answered at least $2 / 3$ of the questions) (Table 1). Interestingly, among the 68 pediatricians (48.5\%) who stated they felt comfortable evaluating and treating patients with FA, only 12 (17.6\%) passed the questionnaire.

\section{Discussion}

In this study, we determined that the food allergy knowledge and experience of pediatricians in Kuwait were unsatisfactory. We have also identified knowledge gaps that pediatricians should be aware of while caring for patients suspected to have FA.

There were noteworthy deficiencies in pediatricians' awareness about the clinical presentations of FA, despite this being the cornerstone for early diagnosis. This results in a significant delay in diagnosis and can lead to increased morbidity. A substantial proportion of participants thought that behavioral disorders, hyperactivity, and chronic urticaria were clinical manifestations of FA. This results in unnecessary dietary restrictions and unwarranted referrals to allergists. In addition, more than $1 / 3$ of participants did not know that IgE-mediated food allergic reactions are rapid in onset and can occur within minutes from the time of ingestion, which could predispose patients to a serious risk of anaphylaxis and mortality.

Participants also had major deficiencies in understanding the diagnostic tools used in the work-up of cases suspected to have FA. For example, approximately $60 \%$ of participants inappropriately believed that food-specific IgG tests are useful in the evaluation of these patients, despite the clear evidence that these tests have no diagnostic value in the work-up of FA [17]. More than 70\% of the participants incorrectly believed that the skin prick test can be used to screen patients for FA by using a broad panel of allergens. Both practices result in an unnecessary financial burden while testing patients who are suspected to have FA. Furthermore, the majority of participants (75\%) were incorrect in believing that eosinophilia is a common finding in food allergy patients. Other studies have been conducted that confirm gaps in the knowledge of diagnostics tools used for FA. One study documented a

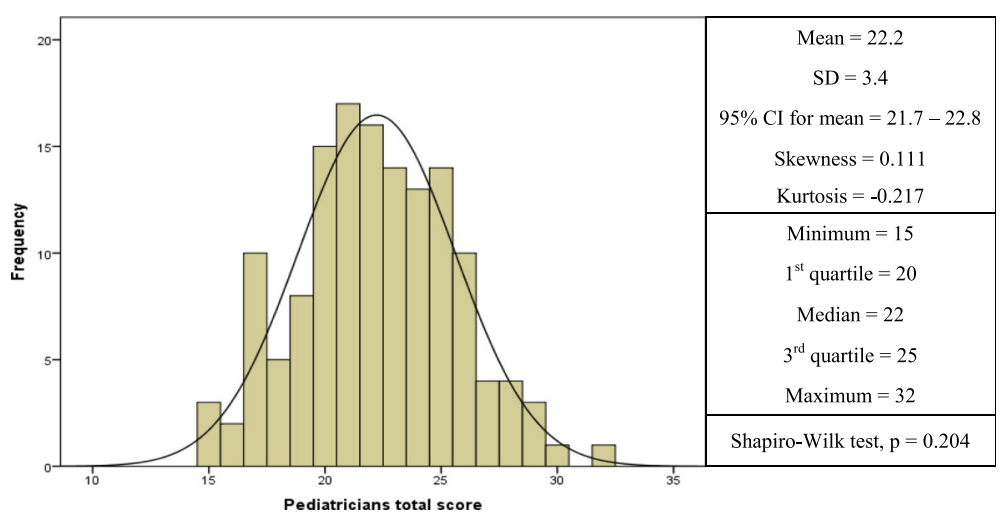

Fig. 1 Frequency distribution of overall knowledge scores of pediatricians in Kuwait regarding food allergy 


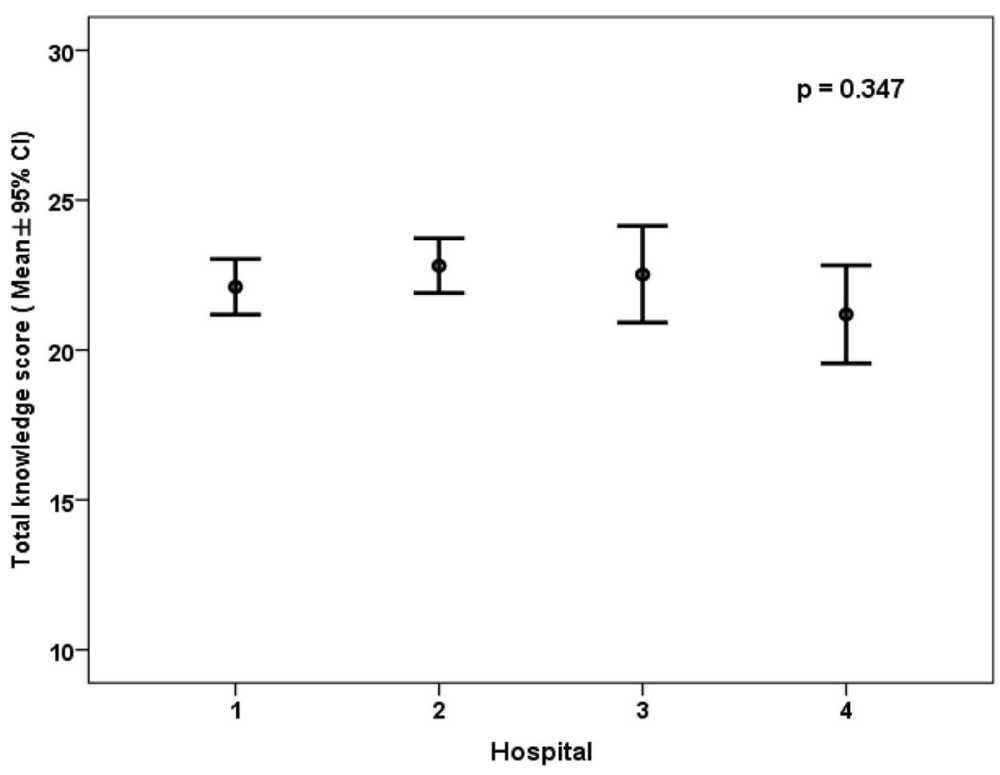

Fig. 2 Mean and 95\% confidence interval of overall scores of pediatricians in Kuwait regarding food allergy according to hospitals

group of pediatricians and primary care physicians in the United States and found that fewer than $30 \%$ of the participants felt comfortable interpreting laboratory tests to diagnose FA [8]. Another study also performed in the United States by Bahna et al. documented deficiencies in the knowledge of non-allergists in the methods used for the diagnosis of FA [9].

In the present study, approximately half of the participants improperly believed that patients with seafood allergies should avoid radiocontrast media used in medical scans due to iodine content. A similar number of participants were under the false impression that dietary restrictions during pregnancy and lactation protects against food allergy development in newborn infants, although the current recommendations are clear in this regard. Furthermore, the majority of participants (68\%) incorrectly believed that the use of soy or amino acid formula early in life prevents the development of food allergies. These findings suggest that the awareness of pediatricians regarding preventive measures against the development of FA is limited and not up to date. Similar results were also

Table 2 Multiple linear regression analysis using total knowledge score as the dependent variable

\begin{tabular}{lccl}
\hline Variable & Coefficient & $p$ value & 95\% confidence interval \\
\hline Age (years) & 0.147 & 0.018 & $0.018-0.026$ \\
Gender & -1.373 & 0.039 & $-2.674--0.071$ \\
Number of years & -0.106 & 0.134 & $-0.245-0.033$ \\
as a pediatrician & & & \\
Rank & 0.298 & 0.249 & $-0.212-0.809$ \\
Hospital & 0.226 & 0.445 & $-0.358-0.811$ \\
\hline
\end{tabular}

documented in a study performed in Brazil, which concluded that there are gaps in the knowledge of professionals about the primary prevention of FA [10].

Limitations of our study should be noted. First, the questionnaire used was not validated and was not tested for reliability. Second, the authors realize that a passing score of $67 \%$ is arbitrary and is not based on scientific background.

Table 3 Percentage of participants who correctly answered the questions in the clinical presentation section

\begin{tabular}{|c|c|}
\hline & Percent \\
\hline $\begin{array}{l}\text { Cow's milk protein allergy is always accompanied by } \\
\text { bloody stools }\end{array}$ & $6.4 \%$ \\
\hline $\begin{array}{l}\text { Cow's milk protein allergy usually presents in the first } \\
\text { week of life }\end{array}$ & $16.4 \%$ \\
\hline $\begin{array}{l}\text { IgE-mediated food allergic reactions are rapid in onset, } \\
\text { typically beginning within minutes to } 2 \mathrm{~h} \text { from the time } \\
\text { of ingestion }\end{array}$ & $63.6 \%$ \\
\hline Chronic urticaria is rarely caused by food hypersensitivity & $37.1 \%$ \\
\hline $\begin{array}{l}\text { Patients with a food allergy almost always have other } \\
\text { atopic manifestations }\end{array}$ & $53.6 \%$ \\
\hline $\begin{array}{l}\text { Chronic wheezing can be the only manifestation of } \\
\text { cow's milk protein allergy }\end{array}$ & $68.6 \%$ \\
\hline $\begin{array}{l}\text { Anaphylaxis caused by food allergy occasionally follows } \\
\text { a biphasic course, with a recurrence of symptoms hours } \\
\text { after the initial onset }\end{array}$ & $73.6 \%$ \\
\hline $\begin{array}{l}\text { Food-related reactions are usually caused by additives/ } \\
\text { coloring added to the food }\end{array}$ & $57.1 \%$ \\
\hline $\begin{array}{l}\text { Behavioral disorders and hyperactivity are frequent } \\
\text { manifestations of a food allergy }\end{array}$ & $34.3 \%$ \\
\hline Infantile colic is rarely caused by a food allergy & $29.3 \%$ \\
\hline
\end{tabular}


Table 4 Percentage of participants who correctly answered the questions in the diagnostics section

\begin{tabular}{ll}
\hline & Percent \\
\hline $\begin{array}{l}\text { Skin prick testing can be used to screen patients for an } \\
\text { allergy by testing with broad panels of food allergens }\end{array}$ & $72.9 \%$ \\
$\begin{array}{l}\text { Skin prick testing is highly sensitive but only moderately } \\
\text { specific }\end{array}$ & $66.4 \%$ \\
$\begin{array}{l}\text { Intradermal skin testing is recommended for the evaluation } \\
\text { of food allergies }\end{array}$ & $58.6 \%$ \\
$\begin{array}{l}\text { Atopy patch testing is helpful in diagnostic workup for } \\
\text { food allergies }\end{array}$ & $65.7 \%$ \\
$\begin{array}{l}\text { Allergen-specific lgE testing is less sensitive than the skin } \\
\text { prick test }\end{array}$ & $31.4 \%$ \\
$\begin{array}{l}\text { Allergen-specific IgE testing is not useful in patients with } \\
\text { severe atopic dermatitis }\end{array}$ & $40.7 \%$ \\
$\begin{array}{l}\text { Food challenges should only be performed by allergy } \\
\text { specialists familiar with food-allergic reactions }\end{array}$ & $81.4 \%$ \\
$\begin{array}{l}\text { Food-specific immunoglobulin G (lgG) and lgG4 tests are } \\
\text { additional useful tests for allergies }\end{array}$ & $59.3 \%$ \\
$\begin{array}{l}\text { A positive skin test to a particular food indicates that the } \\
\text { patient has a true allergy to that food }\end{array}$ & $54.3 \%$ \\
$\begin{array}{l}\text { The best way to test for food allergies is by oral challenge } \\
\text { Elimination diet should be the first step in the evaluation } \\
\text { of a patient presenting with food related anaphylaxis }\end{array}$ & $53.6 \%$ \\
$\begin{array}{l}\text { Eosinophilia is an important/common finding in patients } \\
\text { with a food allergy }\end{array}$ & $79.3 \%$ \\
\hline
\end{tabular}

\section{Conclusions}

We conclude that pediatricians' awareness of FA is unsatisfactorily low in Kuwait. It is true that the survey was conducted at a local level; however, we feel that the results are representative of other countries, given the

Table 5 Percentage of participants who correctly answered the questions in the treatment section

\begin{tabular}{lc}
\hline & Percent \\
\hline $\begin{array}{l}\text { The only available treatment option for food allergic patients } \\
\text { is strict avoidance of the food causing reaction }\end{array}$ & $51.4 \%$ \\
If a patient is diagnosed with food intolerance, he/she may & $53.6 \%$ \\
be able to ingest small quantities without having a reaction & \\
There is currently no cure for food allergies & $55.7 \%$ \\
$\begin{array}{l}\text { The most important step in preventing a reaction is parental } \\
\text { education regarding avoiding coming in contact with food }\end{array}$ & $82.1 \%$ \\
proteins that can cause an allergic reaction & \\
$\begin{array}{l}\text { Reading food labels is usually enough to prevent allergic } \\
\text { reactions, as they are accurate }\end{array}$ & $17.1 \%$ \\
$\begin{array}{l}\text { The prophylactic use of an anti-histamine prevents anaphylaxis } \\
\text { in food allergic patients }\end{array}$ & $13.6 \%$ \\
$\begin{array}{l}\text { All food allergic patients should be referred to nutritional } \\
\text { counseling }\end{array}$ & $69.3 \%$ \\
$\begin{array}{l}\text { Cow's milk allergic patients should be given goat's or sheep's } \\
\text { milk to avoid nutritional deficiency }\end{array}$ & $17.1 \%$ \\
$\begin{array}{l}\text { Patients with a seafood allergy should avoid radio-contrast } \\
\text { media used in medical scans due to iodine content }\end{array}$ & $46.4 \%$ \\
\hline
\end{tabular}

Table 6 Percentage of participants who correctly answered the questions in the prevention section

\begin{tabular}{ll}
\hline & Percent \\
\hline $\begin{array}{l}\text { Dietary restriction during pregnancy and lactation protects } \\
\text { against food allergy development in newborn infants }\end{array}$ & $47.9 \%$ \\
$\begin{array}{ll}\text { Delay of introduction of solid foods after } 4 \text { months of age in } \\
\text { high risk infants reduces the risk of developing a food allergy }\end{array}$ & $74.3 \%$ \\
\end{tabular}

Exclusive breast-feeding may help to prevent a food allergy

$83.6 \%$

For infants at risk for a food allergy who are not exclusively breast-fed, the use of hydrolyzed infant formulas instead of cow's milk formula has a preventive effect on atopic disease and cow's milk protein allergy

Is early introduction of cow milk formula in newborns associated with an increase in the risk of developing a food allergy?

It is highly recommended to use probiotics as supplements for neonates as a way to prevent allergies

The use of soy or amino acid formula early in life prevents the development of a food allergy

$90 \%$

$85.7 \%$

$40 \%$

diverse educational background of pediatricians practicing in Kuwait. Therefore, we recommend an implementation of strategies to improve pediatricians' awareness so that proper interventions and nutritional management can be undertaken to improve patient health and outcomes. These strategies may include comprehensive undergraduate and postgraduate education, organizing continuing medical education (CME) courses, and publishing educational materials (posters, booklets, articles). Special attention should be given to interactive learning by involving pediatricians in the care of food allergy patients. Conducting similar surveys with internists, nutritional specialists, and nurses may provide better data about the awareness of FA among health care providers in Kuwait.

\section{Abbreviation}

FA: Food allergy

\section{Acknowledgements}

None.

\section{Funding}

None.

\section{Availability of data and materials}

The datasets for the current study are available from the corresponding author upon reasonable request.

\section{Authors' contributions}

WA conceptualized and designed the study, participated in the design of the questionnaire, participated in data collection, carried out the initial analyses, drafted the initial manuscript, and approved the final manuscript as submitted. $\mathrm{KH}, \mathrm{AA}$ and FA participated in the design of the questionnaire, participated in data collection, and reviewed and approved the final manuscript as submitted. MM carried out data interpretation and analyses, revised the manuscript, and reviewed and approved the final manuscript as submitted.

\section{Competing interests}

The authors declare that they have no competing interests. 


\section{Consent for publication}

Not applicable.

\section{Ethics approval and consent to participate}

This study was approved by the Research and Ethics Committees of both the Health Sciences Center, Kuwait University and the Ministry of Health in Kuwait. Written informed consent was obtained from the pediatricians for inclusion in the study.

\section{Author details}

'Department of Pediatrics, Faculty of Medicine, Kuwait University, P.O. Box: 24923, Safat, 13110 Kuwait city, Kuwait. ${ }^{2}$ Allergy and Clinical Immunology Unit, Department of Pediatrics, Al-Sabah Hospital, Kuwait City, Kuwait. ${ }^{3}$ Gastroenterology Unit, Department of Pediatrics, Al-Ameri Hospital, Kuwait City, Kuwait. ${ }^{4}$ Allergy and Clinical Immunology Unit, Department of Pediatrics, Mubarak Hospital, Kuwait City, Kuwait. ${ }^{5}$ Department of Community Medicine \& Behavioral Sciences, Faculty of Medicine, Kuwait University, Kuwait City, Kuwait. ${ }^{6}$ Gastroenterology Unit, Department of Pediatrics, Adan Hospital, Kuwait City, Kuwait.

Received: 27 July 2016 Accepted: 30 December 2016

\section{Published online: 11 January 2017}

\section{References}

1. Muraro A, Werfel T, Hoffmann-Sommergruber $\mathrm{K}$, et al. EAACl food allergy and anaphylaxis guidelines: diagnosis and management of food allergy. Allergy. 2014;69(8):1008-25

2. Osborne NJ, Koplin JJ, Martin PE, et al. Prevalence of challenge-proven IgE-mediated food allergy using population-based sampling and predetermined challenge criteria in infants. J Allergy Clin Immunol. 2011:127:668-76.

3. Sicherer SH, Sampson HA. Food allergy. J Allergy Clin Immunol. 2006:117:S470-475.

4. Mackay IR, Rosen FS. Allergy and allergic diseases. N Eng J Med 2001;344:30-7.

5. Cochrane $S$, Beyer $K$, Clausen $M$, et al. Factors influencing the incidence and prevalence of food allergy. Allergy. 2009;64:1246-55.

6. Venter C, Pereira B, Grundy J, et al. Incidence of parentally reported and clinically diagnosed food hypersensitivity in the first year of life. J Allergy Clin Immunol. 2006;117:1118-24.

7. Pyrhönen K, Näyhä S, Kaila M, et al. Occurrence of parent-reported food hypersensitivities and food allergies among children aged 1-4 yr. Pediatr Allergy Immunol. 2009;20:328-38.

8. Sladkevicius E, Nagy E, Lack G, et al. Resource implications and budget impact of managing cow milk allergy in the UK. J Med Econ. 2010;13(1):119-28.

9. Gupta RS, Springston EE, Kim JS, et al. Food allergy knowledge, attitudes, and beliefs of primary care physicians. Pediatrics. 2010;125(1):126-32.

10. Wilson BG, Cruz NV, Fiocchi A, et al. American College of Allergy, Asthma \& Immunology Adverse Reactions to Food Committee. Survey of physicians' approach to food allergy, Part 2: Allergens, diagnosis, treatment, and prevention. Ann Allergy Asthma Immunol. 2008;100(3):250-5.

11. Ribeiro CC, Leite Speridião Pda G, de Morais MB. Knowledge and practice of physicians and nutritionists regarding the prevention of food allergy. Clin Nutr. 2013;32(4):624-9.

12. Gupta RS, Lau CH, Dyer AA, et al. Food allergy diagnosis and management practices among pediatricians. Clin Pediatr. 2014;53(6):524-30.

13. Wang J, Young MC, Nowak-Węgrzyn A. International survey of knowledge of food-induced anaphylaxis. Pediatr Allergy Immunol. 2014;25(7):644-50.

14. Morawetz DY, Hiscock H, Allen K, et al. Management of food allergy: a survey of Australian paediatricians. J Paediatr Child Health. 2014:50(6):432-7.

15. Boyce JA, Assa'ad A, Burks AW, et al. Guidelines for the diagnosis and management of food allergy in the United States: summary of the NIAID-sponsored expert panel report. Nutr Res. 2011;31(1):61-75.

16. Fleischer DM, Spergel JM, Assa'ad AH, et al. Primary prevention of allergic disease through nutritional interventions. J Allergy Clin Immunol Pract. 2013;1(1):29-36

17. Burks AW, Tang M, Sicherer S, et al. ICON: food allergy. J Allergy Clin Immunol. 2012;129(4):906-20.

\section{Submit your next manuscript to BioMed Central and we will help you at every step:}

- We accept pre-submission inquiries

- Our selector tool helps you to find the most relevant journal

- We provide round the clock customer support

- Convenient online submission

- Thorough peer review

- Inclusion in PubMed and all major indexing services

- Maximum visibility for your research

Submit your manuscript at www.biomedcentral.com/submit
) Biomed Central 